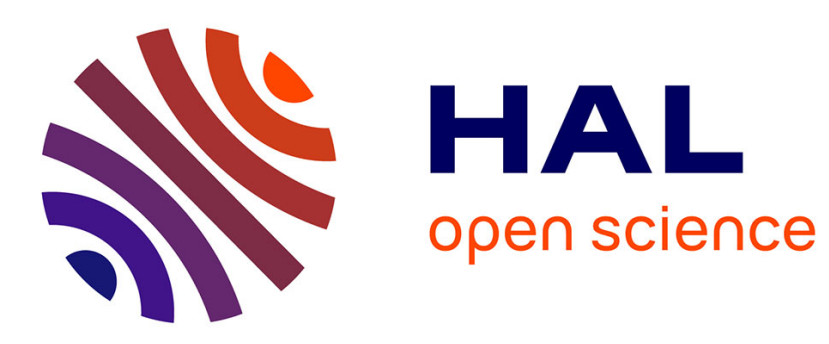

\title{
Further delineation of BCAP31-linked intellectual disability: description of 17 new families with LoF and missense variants
}

Sandra Whalen, Marie Shaw, Cyril Mignot, Delphine Héron, Sandra Chantot Bastaraud, Cecile Cieuta Walti, Jan Liebelt, Frances Elmslie, Patrick Yap, Jane Hurst, et al.

\section{To cite this version:}

Sandra Whalen, Marie Shaw, Cyril Mignot, Delphine Héron, Sandra Chantot Bastaraud, et al.. Further delineation of BCAP31-linked intellectual disability: description of 17 new families with LoF and missense variants. European Journal of Human Genetics, 2021, 10.1038/s41431-021-00821-0 . hal-03149040

\section{HAL Id: hal-03149040 \\ https://hal-amu.archives-ouvertes.fr/hal-03149040}

Submitted on 25 Feb 2021

HAL is a multi-disciplinary open access archive for the deposit and dissemination of scientific research documents, whether they are published or not. The documents may come from teaching and research institutions in France or abroad, or from public or private research centers.
L'archive ouverte pluridisciplinaire HAL, est destinée au dépôt et à la diffusion de documents scientifiques de niveau recherche, publiés ou non, émanant des établissements d'enseignement et de recherche français ou étrangers, des laboratoires publics ou privés. 
1 Further delineation of BCAP31-linked intellectual disability: description of 17

2 new families with LoF and missense variants

3

$4 \quad$ Running title: Description of 17 families with BCAP31 deficiency

5

6 Corresponding author:

7 Sandra Whalen

8 UF de génétique Clinique et Centre de Reference Anomalies du Développement et

9 Syndromes Malformatifs, APHP.Sorbonne Université, Hôpital Armand Trousseau,

10 Paris, France

11 Sandra.whalen@aphp.fr

12 Tel: 0033171738740

\section{Authors:}

15 Sandra Whalen ${ }^{1}$, Marie Shaw ${ }^{2}$, Cyril Mignot ${ }^{3}$, Delphine Héron ${ }^{3}$, Sandra Chantot 16 Bastaraud $^{4}$, Cecile Cieuta Walti ${ }^{5,6}$, Jan Liebelt ${ }^{7}$, Frances Elmslie ${ }^{8}$, Patrick Yap ${ }^{9}$, Jane 17 Hurst $^{10}$, Elisabeth Forsythe ${ }^{10}$, Brian Kirmse ${ }^{11}$, Jillian Ozmore ${ }^{12}$, Alessandro Mauro 18 Spinelli $^{13}$, Olga Calabrese ${ }^{13}$, Thierry Billette de Villemeur ${ }^{14}$, Anne Claude Tabet $^{15}$, 19 Jonathan Levy ${ }^{15}$, Agnes Guet ${ }^{16}$, Manoëlle Kossorotoff ${ }^{17}$, Benjamin Kamien ${ }^{18}$, Jenny 20 Morton $^{19}$, Anne McCabe ${ }^{19}$, Elise Brischoux-Boucher ${ }^{20}$, Annick Raas-Rothschild ${ }^{22}$, 21 Antonella $\mathrm{Pini}^{23}$, Renée Carroll ${ }^{2}$, Jessica N. Hartley ${ }^{24}$, Care4Rare Canada 22 Consortium, Patrick Frosk ${ }^{24}$, Anne Slavotinek ${ }^{25}$, Kristen Truxal ${ }^{26}$, Carroll Jennifer ${ }^{26}$, 23 Annelies Dheedene ${ }^{27}$, Hong Cuil ${ }^{28}$, Vishal Kumar ${ }^{29,30}$, Glen Thomson ${ }^{31}$, Florence 24 Riccardi ${ }^{21,33}$, Jozef Gecz ${ }^{2,32}$, Laurent Villard*21,33

26 1. UF de Génétique Clinique et Centre de Reference Anomalies du Développement 27 et Syndromes Malformatifs, APHP.Sorbonne Université, Hôpital Trousseau, Paris, 28 France

29 2. Adelaide Medical School and Robinson Research Institute, The University of 30 Adelaide, South Australia 5005, Australia

31 3. Département de Génétique et de Cytogénétique et Centre de Référence 32 Déficiences Intellectuelles de Causes Rares, APHP.Sorbonne Université, Paris, 33 France 
4. Département de Génétique, UF de Génétique Chromosomique, APHP, Hôpital Armand Trousseau, Paris, France

5. Institut Jérôme Lejeune, Paris, France

6. IUSSS de l'Estrie-CHUS Université de Sherbrooke, Canada

7. South Australian Clinical Genetics Service, Women's and Children's Hospital, Adelaide, Australia

40 8. South West Thames Regional Genetics Service, St George's University Hospitals, 41 London, UK

42 9. Genetic Health Service New Zealand (Northern Hub), Auckland 1023, New 43 Zealand

44 10. Department of Clinical Genetics, Great Ormond Street Hospital For Children NHS

45 Foundation Trust, London, United Kingdom of Great Britain and Northern Ireland

46 11. Division of Medical Genetics, Department of Pediatrics, University of Mississippi 47 Medical Center, Jackson, MS, USA

48 12. Medical Genetics, Dartmouth-Hitchcock medical center, Lebanon, New 49 Hampshire, USA

50 13. Medical Genetics Unit, University of Modena and Reggio Emilia, Modena, Italy

51 14. Sorbonne Université, service de neuropédiatrie, Hôpital Trousseau, APHP.SU, 52 Inserm U1141, Paris, France

53 15. UF de Cytogénétique, Département de génétique, APHP, Hôpital Robert Debré, 54 Paris, France

55 16. Service de Néonatologie et Pédiatrie, APHP, Hôpital Louis-Mourier, Colombes, 56 France

57 17. Département de Neurologie pédiatrique, AP-HP, Hôpital Necker-Enfants-Malades, 58 Paris, France

59 18. Genetic Services of Western Australia, King Edward Memorial Hospital, Subiaco, 60 Australia

61 19. West Midlands Regional Clinical Genetics Service and Birmingham Health 62 Partners, Birmingham Women's and Children's Hospitals NHS Foundation Trust, UK

63 20. Centre de Génétique Humaine, Université de Franche-Comté, Besançon, France

64 21. Département de génétique médicale, AP-HM, Hôpital d'enfants La Timone, 65 Marseille, France

66 22. Institute for Rare Diseases, Edmond and Lily Safra Children Hospital, Sheba 67 Medical Center, Israel

68 23. Child Neurology and Psychiatry Unit, IRCCS Istituto delle Scienze Neurologiche, 69 Bologna, Italy

70 24. Biochemistry \& Medical Genetics, Max Rady College of Medicine, Rady Faculty

71 of Health Sciences, University of Manitoba, Winnipeg, Canada

72 25. Medical Genetics, Benioff Children's Hospital Oakland, Division of Genetics,

73 Department of Pediatrics, University of California, UCSF Benioff Children's Hospital,

74 San Francisco, USA

75 26. Division of Genetic and Genomic Medicine, Nationwide Children's Hospital and

76 Research Institute, The Ohio State University, Columbus, Ohio, USA

77 27. Center for Medical Genetics, Ghent University Hospital, Ghent, Belgium 
28. GeneDx, 207 Perry Parkway, Gaithersburg, MD 20877, USA

79

29. Department of Radiology and Biomedical Imaging, University of California, San Francisco, 1001 Potrero Ave., San Francisco, CA 94110, USA

30. Zuckerberg San Francisco General Hospital and Trauma Center, San Francisco, California, USA

31. Department of Paediatric Radiology, Starship Children's Hospital, Auckland, New Zealand

32. South Australian Health and Medical Research Institute, Adelaide, South Australia 5000, Australia

33. Aix Marseille Université, Inserm, MMG, U1251, Marseille, France.

*these authors contributed equally to this work

90

91 Conflict of interest: the authors declare that they have no conflict of interest.

92 


\section{Abstract}

94 The BCAP31 gene, located at $\mathrm{Xq28}$, encodes BAP31 which plays a role in ER-to95 Golgi anterograde transport. To date, BCAP31 pathogenic variants have been reported in 12 male cases from 7 families (six loss of function (LoF) and one

97 missense). Patients had severe intellectual disability (ID), dystonia, deafness, and 98 central hypomyelination, delineating a so-called DDCH syndrome (Deafness, 99 Dystonia and Cerebral Hypomyelination). Female carriers are mostly asymptomatic 100 but may present with deafness. BCAP31 is flanked by the SLC6A8 and ABCD1 101 genes. Contiguous deletions of BCAP31 and ABCD1 and/or SLC6A8 have been 102 described in 12 patients. Patients with deletions including BCAP31 and SLC6A8 103 have the same phenotype as BCAP31 patients. Patients with deletions of BCAP31 104 and $A B C D 1$ have Contiguous $A B C D 1$ and $D X S 1375 E / B C A P 31$ Deletion Syndrome 105 (CADDS), and demonstrate a more severe neurological phenotype with cholestatic 106 liver disease and early death. We report 17 novel families, 14 with intragenic 107 BCAP31 variants (LoF and missense) and three with a deletion of BCAP31 and 108 adjacent genes (comprising 2 CADDS patients, one male and one symptomatic 109 female). Our study confirms the phenotype reported in males with intragenic LoF 110 variants and shows that males with missense variants exhibit a milder phenotype. 111 Most patients with a LoF pathogenic BCAP31 variant have permanent or transient 112 liver enzyme elevation. We further demonstrate that carrier females $(n=10)$ may have 113 a phenotype comprising LD, ID and/or deafness. The male with CADDS had a severe 114 neurological phenotype, but no cholestatic liver disease; and the symptomatic female 115 had moderate ID and cholestatic liver disease. 
117 Key words: BCAP31, dystonia, hearing loss, liver disease, DDCH syndrome, 118 intellectual disability

119

120 


\section{INTRODUCTION}

122 The BCAP31 gene (MIM 300398) is located at Xq28 and encodes B-cell-receptor-

123 associated protein 31 (BAP31), a ubiquitous $31 \mathrm{kDa}$ chaperone protein highly

124 expressed in neurons (1). It is the most abundant of endoplasmic reticulum (ER)

125 membrane proteins (2) and plays a role in regulation of apoptosis, protein transport

126 and degradation. BAP31 has a role in the export of secreted proteins $(3,4)$, and their

127 targeting to the ER-associated-degradation pathway (ERAD) $(5,6)$. BAP31 also

128 serves as a cargo receptor for the export of transmembrane proteins. (1).

129

130 In 2013, Cacciagli et al (7) described a specific phenotype associated with BCAP31

131 loss of function (LoF) anomalies in seven males from three families with severe to

132 profound developmental delay (DD) or intellectual disability (ID), dystonia, seizures,

133 sensorineural hearing loss (SNHL) and central myelination delay which defined the

134 DDCH syndrome (for Deafness, Dystonia and Cerebral Hypomyelination, MIM

135 300475). In all instances, the pathogenic BCAP31 variants were inherited from

136 asymptomatic mothers. Functional studies were undertaken on patient fibroblasts

137 and supported the evidence that BAP31 plays a role in ER-to-Golgi exchanges. No

138 evidence of accumulation of misfolded proteins or activation of either UPR or cell-

139 death programs was found. It was hypothesized that the key role of ER protein

140 trafficking in the myelination process (8) could explain the white matter abnormalities.

141 Four additional male patients from three families with BCAP31 LoF anomalies and a

142 similar phenotype were subsequently reported (9-11). Vittal et al reported two

143 affected brothers (twins) with a 6 bp deletion in c.261_266delGCTTCT

144 (c.60_65delGCTTCT according to reference transcript NM_001139441.1) resulting in

145 a protein change of p.(Leu87_Leu89delinsPhe) (p.(Leu20_Leu22delinsPhe) 
146 according to the protein produced by transcript NM_001139441.1) that can be

147 considered as a missense variant (12). The phenotype of one of the two brothers is

148 milder than in previously described patients with BCAP31 LoF variants, as he 149 acquired partial language and basic academic skills.

150 Liver enzymes were elevated in half of the reported patients, either permanently or

151 intermittently, sometimes during febrile episodes. Patients with pathogenic BCAP31

152 variants/intragenic deletions did not display cholestasis or hepatic failure, except one

153 with acute liver cytolysis and cholestasis concomitant to an episode of intestinal

154 necrosis (11). All female carriers reported to date were asymptomatic, except one 155 with isolated SNHL (9).

156 BCAP31 is flanked by SLC6A8 (MIM 300036) on its centromeric side, and ABCD1 157 (MIM 300371) on its telomeric side. Contiguous deletions of BCAP31 and ABCD1 158 and/or SLC6A8 have been described. Pathogenic ABCD1 LoF variants are 159 responsible of X-linked adrenoleukodystrophy, a neurodegenerative condition that 160 affects the central nervous system white matter and the adrenal cortex, that can 161 reveal itself in childhood (cerebral form) or adulthood (adrenomyeloneuropathy) (13).

162 The childhood onset of the disease is characterized by progressive impairment of 163 cognition, behavior, vision, hearing, and motor function. However, neurodegeneration 164 does not start before 2.7 years. Pathogenic SLC6A8 LoF variants result in cerebral 165 creatine deficiency and the patients display mild to severe ID, seizures and 166 behavioral problems (14). Sensorineural hearing loss, dystonia and chorea are rare. 167 Patients with deletions of $B C A P 31$ and $A B C D 1$ have Contiguous $A B C D 1$ and 168 DXS1375E (BCAP31) Deletion Syndrome (CADDS, MIM 300475) (15). The six male 169 patients described with CADDS had common signs with DDCH, such as severe DD, 170 dystonia, white matter abnormalities and deafness. However, all of these six patients 
171 had chronic cholestatic liver disease, and a more severe course of the disease, as all 172 died in the first year of life (15-19). The only symptomatic female with a deletion 173 encompassing both $B C A P 31$ and $A B C D 1$ reported to date is a 9-year-old girl with 174 severe ID, autism spectrum disorder, microcephaly and deafness, but without white 175 matter anomalies or dystonia (20).

176 Six patients with a deletion including BCAP31 and SLC6A8 have been described 177 (including a family of four patients described by Cacciagli et al) $(7,18,21)$. Their 178 phenotype was more severe than most patients with pathogenic SLC6A8 variants, 179 and they had symptoms and signs similar to BCAP31 patients, such as dystonia, 180 choreoathetosis, SNHL and white matter abnormalities, which are unusual in cerebral 181 creatine deficiency. Thus, most of their phenotype was ascribed to the deletion of 182 BCAP31 (7).

183

184 We assessed 17 novel families with BCAP31 anomalies, 14 families with intragenic 185 LoF or missense variants (16 males and 9 symptomatic females) and three families 186 with a deletion of BCAP31 and adjacent genes (comprising two CADDS patients, one 187 male and a symptomatic female). The symptomatic female carriers had SNHL and/or 188 DD/ID. We also describe two asymptomatic female carriers with somatic mosaicism 189 which is particularly relevant for genetic counselling.

\section{PATIENTS AND METHODS}

192 Male and female individuals with BCAP31 variants and deletions were recruited from 193 different cohorts through national and international collaborations. For two families, 194 the patients were part of a cohort of cerebral palsy patients. 
195 Genetic testing was performed by chromosomal microarray ( $\mathrm{n}=3$ deletions), whole-

196 genome sequencing $(n=1)$, whole-exome sequencing $(n=8)$, TrueSight One gene 197 panel $(n=1), X$ chromosome sequencing $(n=1)$, targeted gene panel for ID $(n=1)$, 198 targeted gene panel for mitochondrial diseases $(n=1)$, or direct Sanger sequencing of $199 \operatorname{BCAP31}(\mathrm{n}=1)$.

200 Variants were annotated using NM_001139441.1 as a reference sequence and were 201 classified according to the ACMG criteria $(22,23)$. Exons are numbered according to 202 Cacciagli et al. 2013. and correspond to transcript ENST00000458587.8.

203 Intragenic variants were submitted to the gene variant database LOVD at 204 https://databases.lovd.nl/shared/individuals/BCAP31 (Patients 1 to 11: individuals 20500315922 to 00315932 , Patient 12: individual 00317967, Patient 13: individual 206 00315934, Patient 14: individual 00314857, Patients 15 to 18: individuals 00314696 207 to 00314699). Large deletions including BCAP31 and adjacent genes were submitted 208 to ClinVar at https://www.ncbi.nlm.nih.gov/clinvar (Patients 19 to 21: individuals 209 SCV001450740 to SCV001450742).

210 Each patient's referring physician filled out a table with detailed general data, family 211 history, pregnancy and labor, neonatal period, developmental milestones, 212 neurological signs, behavioral and epilepsy history, and other detailed clinical history 213 or features (senses, liver, cardiac and respiratory). When possible, pictures and/or 214 videos of the patients and brain MRI were reviewed.

215 Parental written informed consent was obtained for all affected patients. Genetic 216 testing was performed in accordance with the respective national ethics guidelines 217 and approved by the local authorities in the participating study centers.

\section{RESULTS}




\section{Male patients with intragenic variants of BCAP31}

221 Male patients with LoF variants

222 A total of 12 males from 11 families had intragenic LoF variants (Table 1, P1 to P12

223 Families 1 to 11, and Figure 1), that were all maternally inherited except one that was

224 de novo. Somatic mosaicism was found in the mother of P12.

225 The median age of these patients at last examination was 9 years 5 months (2.4 to 22628 years), and all but one were alive at the time of the study. All patients presented 227 with severe to profound DD, none achieved walking, all had absent or limited speech, 228 and all but one had limited or no purposeful use of hands. Neurological examination 229 showed dystonic postures and/or choreic movements (12/12), microcephaly (7/11) 230 and increased muscle tone/pyramidal signs (6/11). The diagnosis of cerebral palsy 231 was initially considered in P5. Seizures were seen in 3/12 patients (petit mal for one, 232 not detailed in the 2 others). The disease appeared to be progressive for two patients. 233 Brain MRI was abnormal in 9/11 patients. White matter (WM) anomalies were the 234 most frequent (7/11), and were described as reduced WM volume, myelination delay, 235 hypomyelination and WM hyperintensities. These anomalies disappeared with time in 236 one patient at the ag of 12 years. Other reported anomalies were cortical atrophy 237 (4/11), thin corpus callosum (3/9), atrophy of basal ganglia and thalami (2/11) and 238 hypoplastic cerebellar vermis (2/11).

239 Moderate to profound SNHL was seen in 9/10 (with normal inner ear CT scan for one 240 patient) and strabismus was frequent (6/11). Small stature (-2SD or below) was seen 241 in $7 / 12$ patients, with weight on -2SD or below in $6 / 12$. Some common facial features 242 were noted such as hypotonic face and deep-set eyes. Unexplained fever was 243 reported in two patients. No major cardio-respiratory anomalies were reported. 
244 Liver enzymes were increased in $8 / 10$, either transiently $(n=4)$ or permanently $(n=4)$.

245 Two patients (P7 and P12) underwent liver biopsy, that showed mild to moderate

246 mononuclear portal tract inflammatory infiltrate consistent with mild chronic hepatitis

247 in P7, and mitochondrial inclusions with a regular/periodic pattern in P12. The latter

248 finding could represent abnormalities of cristae and gave an overall morphology of

249 crystalline inclusions. Mitochondrial complex activities were normal in the fibroblast of

250 two brothers (P2 and P3). CSF neurotransmitters showed mild cerebral folate

251 deficiency (5-MTHF $30 \mathrm{nM}$, normal 40-187 nM) in one patient (P10). He was treated

252 with oral folinic acid with minimal clinical effect.

253 Detailed molecular results of these patients are presented in Figure 1. Interestingly,

254 the variant c.365_366del was found in unrelated patients P5 and P10.

\section{Male patients with missense variants}

257 Four male patients from two families had missense variants (Table 2, P14 to P17, 258 Families 13 and 14, and Figure 1). Median age at last examination was 19.25 years 259 (3 years to 36 years) and all but one were alive at the time of the study.

260 The patients had mild (1/4), moderate (1/4) or severe (2/4) DD/ID. Unsupported 261 sitting was achieved in $3 / 3$, assisted walking for $2 / 3$, all had partial language skills 262 (words for three, sentences for one), and three patients attended a special needs 263 school, one was reported to be able to read simple texts. Dystonic postures and/or 264 choreic movements were seen in all patients and two had increased muscle 265 tone/pyramidal signs. The diagnosis of cerebral palsy was initially considered in 266 these patients. The use of hands was reported to be purposeful for one. 267 Microcephaly was seen in $1 / 3$. None of these patients had seizures or apparent 268 progressive course of the disease. For P14, brain MRI was normal at 14 months. 
269 SNHL was seen in P14 with normal inner ear CT scan, and conductive hearing loss

270 was found in P15. No ophthalmological data was obtained and no liver dysfunction

271 was reported. Two patients had persistent failure to thrive. P14 had a hypotonic face.

272 His supposedly affected uncle had deep-set eyes with high and narrow nasal bridge,

273 similar to other DDCH patients. No specific facial features were noted for the patients

274 of family 14.

275 In P14 (Family 13), the NM_001139441.1:c.47T>A ; p.(Val16Asp) missense variant

276 affects a highly conserved amino-acid within the B-cell receptor-associated 31-like

277 domain, is not reported in gnomAD and is estimated disease causing by

278 pathogenicity predictors. This variant is not reported in gnomAD.

279 In P15 (Family 14), X chromosome exome sequencing identified 16 variants in total, 280 including the $B C A P 31$ variant Hg38: chrX:153715545G>T, 281 NM_001139441.1:c.338C>A. After in silico analysis, all variants except BCAP31 282 were not flagged for follow up. This variant affects a moderately conserved serine 283 residue located in the BAP31 superfamily domain. It is not present in gnomAD and 284 has a CADD (phred) of 23.5. Preliminary data in P18, a symptomatic female (direct 285 cousin of P15), suggests that her fibroblasts have larger/more swollen ER than 286 controls, and abnormal golgi staining (data not shown). The most substantial 287 evidence for the pathogenicity of the variant in this family is its presence in all 288 symptomatic individuals and carrier mothers. However, according to ACMG criteria, 289 these two missense variants remain classified as VUS to date.

\section{Symptomatic female carriers of intragenic BCAP31 anomalies}

292 Females with LoF variants. 
293 Three carrier mothers were symptomatic, two with SNHL (family 2 and 4), and one 294 with apparent mild ID (family 3).

295 P13 was the only affected individual in family 12 and had severe ID, achieved sitting 296 at 18 months, walking at 4 years, and had limited speech at 7 years. She had 297 microcephaly and lower limb spasticity, but no dystonia, chorea or seizures. She had 298 hearing loss and persistent strabismus. She had deep set eyes with high and narrow 299 nasal bridge. Brain MRI at 3 years old showed thin corpus callosum, enlarged 300 cisterna magna, enlarged subarachnoid frontal space but no white matter anomalies. 301 Liver function was normal. X-inactivation studies in peripheral blood showed 302 significant bias at the FRAXA locus (93/7 \%) and 88/12 \% at the HUMARA locus. Her

303 mother was found to have a somatic mosaicism for the pathogenic BCAP31 variant $304(3 \%)$.

305

306 Females with missense variants.

307 In Family 13, the four confirmed female carriers had isolated SNHL. X-inactivation 308 chromosome studies in peripheral blood were inconclusive, showing moderate 309 skewing in one (90/10), no skewing for the second and uninformative results in the 310 third.

311 In Family 14, a carrier female (Table 2, P18) had global DD, acquired walking at age 31217 months and had language delay. She had mild ID, attended a special needs 313 school and could read. She had mild ataxic gait and drop attacks, but no dystonia or 314 chorea. Mild conductive hearing loss was noted in infancy as well as atypical retinal 315 pigmentation. No specific facial features were noted. No data was obtained for liver 316 function. X-inactivation was random in peripheral blood, but skewed toward the 317 variant allele in cultured fibroblasts, as sequencing of the BCAP31 transcript from 
318 fibroblast cDNA, showed only presence of the variant transcript. Functional studies

319 were undertaken on the fibroblasts showing mildly altered ER and Golgi as described by Cacciagli et al but were not statistically significant (data not shown).

\section{Patients with deletion of BCAP31 and adjacent genes (Table 3 and Figure 2)}

324 P19 (Family 15), had a de novo deletion including BCAP31, SLC6A8, DUSP9, PNCK 325 (NC_000023.10:g.(152886255_152976269)del). He had profound DD, infantile 326 spasms, pyramidal signs but no dystonia or chorea. Brain MRI at 2 years old showed abnormal WM and global atrophy. SNHL was diagnosed at birth. Growth was normal including OFC. He had no cholestatic liver disease, however developed reversible acute liver failure during a lung infection that lead to sepsis.

\section{Male patient with CADDS}

332 P20 (Family 16) had a de novo $60 \mathrm{~kb}$ deletion including BCAP31, $A B C D 1$ and 333 PLXNB3 (NC_000023.10:g.(152982350_153041544)del). He had severe DD with no 334 acquired milestones at 16 months, choreic movements and frequent opisthotonus. 335 Brain MRI at 1 month and 10 months showed thalamic hyperintensities with normal 336 WM. He had permanent moderate liver enzyme elevation, but no cholestasis. He had 337 normal hearing, bilateral strabismus, episodes of unexplained fever and recurrent 338 respiratory infections. He was born with severe IUGR followed by severe growth 339 impairment. He was treated for adrenal and exocrine pancreatic deficiency. Lung CT 340 was undertaken at 15 months because of chronic hypoxia and showed unexplained 341 interstitial lung infiltrate. He died of respiratory failure at 16 months. 
344 P21 (Family 17) had a deletion including SLC6A8, BCAP31, exon 1 of $A B C D 1$, 345 DUSP9, PCNK (NC_000023.10:g.(152882907_152991027)del). She was adopted 346 and parental analysis could not be performed. She had moderate ID, walked at 24 347 months and said a few words at 3 years. She had no seizures and no microcephaly. 348 Brain MRI at 15 months showed diffuse WM abnormalities predominant in 349 periventricular region and global atrophy. Spectroscopy showed reduced creatine 350 peak at $50 \%$ due to SLC6A8 deletion. She also had a SNHL, strabismus and 351 hypermetropia. Liver dysfunction was reported with chronic cholestasis, moderate 352 hepatic failure, transient episodes of liver enzyme elevation, and liver biopsy showed 353 signs of cholangiopathy.

\section{Discussion}

\section{Males with intragenic pathogenic BCAP31 variants}

357 The phenotype of the 12 males of this study with intragenic LoF variants is similar to 358 that of previously described cases, hereby confirming a homogeneous clinical 359 involvement in all reported cases to date. The pathogenic BCAP31 variants were 360 inherited in 10 families, and one mother displayed somatic mosaicism (patient 12). All 361 male patients displayed severe DD/ID with no walking, absent or very limited 362 language skills and dystonia or chorea. Microcephaly and increased muscle 363 tone/pyramidal signs were frequent. Seizures were present in few individuals and two 364 patients had an apparently progressive course of disease which has not yet been 365 reported. Common facial features were noted in some patients with hypotonic face 366 and deep set eyes with narrow and high nasal bridge, the latter seemed to be more

367 obvious with time (Figure 3). Physicians considered the diagnosis of cerebral palsy in 
P5 (LoF variant), in individuals of Family 14 (missense variant) and in a presumably

369 affected relative of $\mathrm{P} 14$. Hence, it would be relevant to search for pathogenic $370 B C A P 31$ variants in patients presenting with unexplained cerebral palsy. As in

371 previous patients, brain MRI frequently showed abnormal WM (Figure 4). P2 showed

372 surprising results over time, with myelination delay at 9 months, WM hyperintensities

373 at 10 years, and normalized WM at 12 years old. It would be interesting to repeat the

$374 \mathrm{MRI}$ in other patients to further characterize WM changes during the course of the

375 disease. Other signs were reported but inconsistent, including cortical atrophy, thin

376 corpus callosum, basal ganglia anomalies (atrophic, small, hyperintense on T2

377 weighted MRI sequences), and hypoplastic cerebellar vermis. SNHL was a frequent

378 feature, and the inner ear was radiologically normal in two patients, it would be

379 interesting to confirm this observation in additional patients.

380 As for molecular results, we report the first recurrent pathogenic LoF variant to our

381 knowledge (c.365_366del). We report two further families with missense variants and 382 suggestive clinical presentation, but that remain classified as VUS. The ID in the four 383 males of these families was less severe than in LoF patients, similar to the patients 384 described by Vittal et al (12) thus a milder functional effect of the missense variants 385 could be speculated to explain the milder intellectual disability. However, more 386 patients and functional assessment of these variants are needed to support their 387 involvement in the phenotype.

\section{Symptomatic female carriers of intragenic BCAP31 variants}

390 Our results substantiate the findings of Albanyan et al (9) who described a carrier 391 female with SNHL. Six females in our study also had SNHL, two with LoF variants, 392 and four with missense variants. Interestingly, Rosenberg et al (24) identified a 
393 patient with non-syndromic hearing loss (the sex of the patient was not mentioned)

394 harboring a de novo duplication including BCAP31 and SLC6A8. Altogether, these 395 data suggest that BCAP31 anomalies should be considered in females with non396 syndromic hearing loss. It would be relevant for genetic counselling for female 397 carriers, to consider the risk of having a severely affected male. Sensorineural 398 hearing loss (SNHL) being the most common congenital sensory deficit, with an 399 estimated prevalence of $2-3$ cases per 1,000 individuals it seems important to rule 400 out other causes, genetic or not, before confirming the implication of BCAP31. 401 Approximately half of SNHL in children is due to genetic causes, with $70 \%$ being non402 syndromic. Variations in the GJB2 gene is the most common cause of nonsyndromic 403 genetic SNHL in many populations, however there is high genetic and allelic 404 heterogeneity, with over 100 implicated genes, which can be recessive, dominant, X405 linked or mitochondrial $(25,26)$.

406

407 We also report the first female carriers with mild (two carrier mothers) or severe ID 408 (one proband). We have limited data describing the brain MRI in females, and further 409 data is necessary to speculate about WM abnormalities in these cases. No specific 410 facial features were noted in female carriers except for patient 13 who had severe ID 411 and displayed deep set eyes and narrow nasal bridge.

413 Patients with deletion of BCAP31 and adjacent genes (CADDS and non414 CADDS)

415 The phenotype of the male patient of this study with a non-CADDS deletion including 416 BCAP31 and SLC6A8 was similar to patients with a pathogenic intragenic LoF 417 BCAP31 variant, and more severe than patients with SLC6A8 deficiency, supporting 
418 the evidence that $B C A P 31$ is the major gene responsible for the phenotype, as

419 discussed by previous authors $(7,19)$.

420 The phenotype of the male patient of our study with CADDS is consistent with

421 previously published cases, with severe DD, dystonia, choreic movements and early

422 death. Unlike other CADDS patients, WM was normal, however thalamic

423 hyperintensities were noted, and hearing was normal. Unreported signs were seen in

424 our patient, such as unexplained lung interstitial infiltrate and exocrine pancreatic 425 deficiency.

426 Finally, we report the second female with a deletion of $A B C D 1$ and $B C A P 31$. Both

427 patients had ID, moderate in this study and severe with ASD for the patient described

428 by Firouzabadi et al (20). Both had SNHL. Neither had dystonia or chorea. The

429 patient in this study also had cholestatic liver disease and WM abnormalities, as in

430 male CADDS patients.

431 The large deletions in the three patients of this study also involve adjacent genes, as

432 in previously reported patients. It is possible that other genes deleted in our patients 433 and those of the literature, such as PNCK, DUSP9, PLXNB3, could also contribute to

434 the phenotype, however no data is available to support or exclude this hypothesis to 435 date.

437 Liver phenotype in BCAP31 deficiency

438 Patients with intragenic BCAP31 anomalies have frequent liver enzyme elevation, 439 either permanently or intermittently, sometimes during febrile episodes. P20 (non440 CADDS deletion) displayed a unique episode of acute hepatic failure during valproic 441 acid treatment. BCAP31 has been shown to play a role in lipid metabolism in the liver. 442 Alteration of BCAP31 in mice leads to elevated lipid storage and subsequent 
443 inflammation $(27,28)$. Interestingly, two patients with LoF BCAP31 variants displayed

444 anomalies on liver biopsy, with liver inflammation for P7, and mitochondrial inclusions

445 suggesting a mitochondrial disorder for P12. Shimizu et al (11) and Albanyan et al (9)

446 had already suggested that BCAP31 deficiency shared similarities with mitochondrial

447 disorders, regarding their patients who presented with bilateral hyperintensities of

448 globus pallidus and mitochondrial anomalies on muscle biopsy (9) or complex I deficit

449 in fibroblasts (11). Further exploration in patients with BCAP31 deficiency would be of

450 interest to understand the physiopathology, especially regarding the liver, and to

451 search for signs of mitochondrial dysfunction.

452 No patients with BCAP31 intragenic anomalies or non-CADDS deletions had chronic

453 cholestatic liver disease, as described in the patients with CADDS. This cholestatic

454 disease is suggested to be linked to the deletion of both $B C A P 31$ and $A B C D 1$ with a

455 supposed synergistic effect, however there is no explanation of the mechanism up to

456 date. The male patient in our study with CADDS had no cholestatic disease at 16

457 months, but had permanent moderate liver enzyme elevation. Liver biopsy in P21,

458 the affected female CADDS carrier, showed signs of cholangiopathy.

459 Further data is needed to understand the potential liver dysfunction in BCAP31 460 deficiency and CADDS patients. In the meantime, we suggest monitoring liver 461 function carefully in BCAP31 patients and it is suggested to administer with caution 462 potential hepatotoxic drugs. Valproic acid should be avoided in BCAP31 patients 463 regarding the liver failure in one of our patients. No complication has been reported 464 for acetaminophen to date, and patient 20 frequently received acetaminophen for 465 unexplained fever with no evident change of his liver function, however careful 466 monitoring could be suggested. 
468 In summary, we report 17 novel families with pathogenic BCAP31 variants, including

46914 families with LoF variants, two families with missense variants and three families

470 with large deletions (two with CADDS and one non-CADDS). We confirm the

471 phenotype of $B C A P 31$ deficiency in males, with a possible milder effect of missense

472 variants. We describe symptomatic female carriers with SNHL and/or ID, and more

473 studies are needed to further delineate their phenotype. In most affected male

474 patients, the variant is inherited from the mother, and the description of two

475 asymptomatic carrier females with somatic mosaicism prompts to give careful genetic

476 counselling concerning the recurrence risk.

477

478 Acknowledgments and funding

479 - Hong Cui is an employee of GeneDx, Inc

480 - Jozef Gecz was supported by NHMRC grants APP1155224 and APP1091593 and

481 Channel 7 Children's Research Foundation.

482 - Anne Slavotinek's research reported in this publication was supported by the 483 National Human Genome Research Institute of the National Institutes of Health under 484 Award Number U01HG009599. The content is solely the responsibility of the authors 485 and does not necessarily represent the official views of the National Institutes of 486 Health. Amendola et. al. American Journal of Human Genetics. 2018 Sep 487 6;103(3):319-327. doi: 10.1016/j.ajhg.2018.08.007

488

REFERENCES

490 1. Manley HA, Lennon VA. Endoplasmic reticulum membrane-sorting protein of 491 lymphocytes (BAP31) is highly expressed in neurons and discrete endocrine cells. J 492 Histochem Cytochem Off J Histochem Soc. oct 2001;49(10):1235043.

493 2. Bell AW, Ward MA, Blackstock WP, Freeman HN, Choudhary JS, Lewis AP, et 494 al. Proteomics characterization of abundant Golgi membrane proteins. J Biol Chem. 49516 févr 2001;276(7):5152目65. 
496 3. Annaert WG, Becker B, Kistner U, Reth M, Jahn R. Export of cellubrevin from 497 the endoplasmic reticulum is controlled by BAP31. J Cell Biol. 15 déc 498 1997;139(6):13970410.

499 4. Paquet M-E, Cohen-Doyle M, Shore GC, Williams DB. Bap29/31 Influences 500 the Intracellular Traffic of MHC Class I Molecules. J Immunol. 15 juin $5012004 ; 172(12): 7548$ ?55.

502 5. Geiger R, Andritschke D, Friebe S, Herzog F, Luisoni S, Heger T, et al. BAP31 503 and BiP are essential for dislocation of SV40 from the endoplasmic reticulum to the 504 cytosol. Nat Cell Biol. nov 2011;13(11):1305?14.

505 6. Wakana Y, Takai S, Nakajima K, Tani K, Yamamoto A, Watson P, et al. Bap31 506 Is an Itinerant Protein That Moves between the Peripheral Endoplasmic Reticulum 507 (ER) and a Juxtanuclear Compartment Related to ER-associated Degradation. 508 Linstedt A, éditeur. Mol Biol Cell. mai 2008;19(5):1825?36.

509 7. Cacciagli P, Sutera-Sardo J, Borges-Correia A, Roux J-C, Dorboz I, 510 Desvignes J-P, et al. Mutations in BCAP31 cause a severe X-linked phenotype with 511 deafness, dystonia, and central hypomyelination and disorganize the Golgi apparatus. 512 Am J Hum Genet. 5 sept 2013;93(3):579?86.

513 8. Roboti P, Swanton E, High S. Differences in endoplasmic-reticulum quality 514 control determine the cellular response to disease-associated mutants of proteolipid 515 protein. J Cell Sci. 1 nov 2009;122(Pt 21):3942?53.

516 9. Albanyan S, Al Teneiji A, Monfared N, Mercimek-Mahmutoglu S. BCAP31517 associated encephalopathy and complex movement disorder mimicking 518 mitochondrial encephalopathy. Am J Med Genet A. juin 2017;173(6):1640?3.

519 10. Rinaldi B, Van Hoof E, Corveleyn A, Van Cauter A, de Ravel T. BCAP31520 related syndrome: The first de novo report. Eur J Med Genet. 19 juill 2019;103732.

521 11. Shimizu K, Oba D, Nambu R, Tanaka M, Oguma E, Murayama K, et al. 522 Possible mitochondrial dysfunction in a patient with deafness, dystonia, and cerebral 523 hypomyelination (DDCH) due to BCAP31 Mutation. Mol Genet Genomic Med. 2020 524 Mar;8(3):e1129.

525 12. Vittal P, Hall DA, Dames S, Mao R, Berry-Kravis E. BCAP31 Mutation Causing 526 a Syndrome of Congenital Dystonia, Facial Dysorphism and Central Hypomyelination 527 Discovered Using Exome Sequencing. Mov Disord Clin Pract. avr 2016;3(2):19709.

528 13. Engelen M, Kemp S, de Visser M, van Geel BM, Wanders RJ, Aubourg P, et 529 al. X-linked adrenoleukodystrophy (X-ALD): clinical presentation and guidelines for 530 diagnosis, follow-up and management. Orphanet J Rare Dis. 2012;7(1):51.

531 14. van de Kamp JM, Betsalel OT, Mercimek-Mahmutoglu S, Abulhoul L, 532 Grünewald S, Anselm I, et al. Phenotype and genotype in 101 males with X-linked 533 creatine transporter deficiency. J Med Genet. juill 2013;50(7):463 72.

534 15. Corzo D, Gibson W, Johnson K, Mitchell G, LePage G, Cox GF, et al. 535 Contiguous Deletion of the X-Linked Adrenoleukodystrophy Gene (ABCD1) and 536 DXS1357E: A Novel Neonatal Phenotype Similar to Peroxisomal Biogenesis 537 Disorders. Am J Hum Genet. juin 2002;70(6):1520?31.

538 16. Calhoun ARUL, Raymond GV. Distal Xq28 microdeletions: clarification of the 539 spectrum of contiguous gene deletions involving ABCD1, BCAP31, and SLC6A8 with 540 a new case and review of the literature. Am $J$ Med Genet $A$. oct $541 \quad 2014 ; 164 \mathrm{~A}(10): 2613$ ? 7.

542 17. Iwasa M, Yamagata T, Mizuguchi M, Itoh M, Matsumoto A, Hironaka M, et al. 543 Contiguous ABCD1 DXS1357E deletion syndrome: report of an autopsy case. 544 Neuropathol Off J Jpn Soc Neuropathol. juin 2013;33(3):292?8.

545 18. Osaka H, Takagi A, Tsuyusaki Y, Wada T, lai M, Yamashita S, et al. 
546 Contiguous deletion of SLC6A8 and BAP31 in a patient with severe dystonia and 547 sensorineural deafness. Mol Genet Metab. mai 2012;106(1):43? 7.

548 19. van de Kamp JM, Errami A, Howidi M, Anselm I, Winter S, Phalin-Roque J, et

549 al. Genotype-phenotype correlation of contiguous gene deletions of SLC6A8, 550 BCAP31 and ABCD1. Clin Genet. févr 2015;87(2):141?7.

551 20. Firouzabadi SG, Kariminejad R, Vameghi $R$, Darvish $H$, Ghaedi $H$, 552 Banihashemi S, et al. Copy Number Variants in Patients with Autism and Additional 553 Clinical Features: Report of VIPR2 Duplication and a Novel Microduplication 554 Syndrome. Mol Neurobiol. nov 2017;54(9):7019?27.

555 21. Anselm IM, Alkuraya FS, Salomons GS, Jakobs C, Fulton AB, Mazumdar M, 556 et al. X-linked creatine transporter defect: A report on two unrelated boys with a 557 severe clinical phenotype. J Inherit Metab Dis. févr 2006;29(1):21409.

558 22. Nykamp K, Anderson M, Powers M, Garcia J, Herrera B, Ho Y-Y, et al. 559 Sherloc: a comprehensive refinement of the ACMG-AMP variant classification criteria. 560 Genet Med Off J Am Coll Med Genet. 2017;19(10):1105?17.

561 23. Richards S, Aziz N, Bale S, Bick D, Das S, Gastier-Foster J, et al. Standards 562 and guidelines for the interpretation of sequence variants: a joint consensus 563 recommendation of the American College of Medical Genetics and Genomics and 564 the Association for Molecular Pathology. Genet Med Off J Am Coll Med Genet. mai 565 2015;17(5):405024.

566 24. Rosenberg C, Freitas ÉL, Uehara DT, Auricchio MTBM, Costa SS, Oiticica J, 567 et al. Genomic copy number alterations in non-syndromic hearing loss. Clin Genet. 568 avr 2016;89(4):473?7.

569 25. Alford RL, Arnos KS, Fox M, Lin JW, Palmer CG, Pandya A, et al. American 570 College of Medical Genetics and Genomics guideline for the clinical evaluation and 571 etiologic diagnosis of hearing loss. Genet Med Off J Am Coll Med Genet. avr 572 2014;16(4):347?55.

573 26. Oza AM, DiStefano MT, Hemphill SE, Cushman BJ, Grant AR, Siegert RK, et 574 al. Expert specification of the ACMG/AMP variant interpretation guidelines for genetic 575 hearing loss. Hum Mutat. 2018;39(11):15930613.

576 27. Wu Z, Yang F, Jiang S, Sun X, Xu J. Induction of Liver Steatosis in BAP31577 Deficient Mice Burdened with Tunicamycin-Induced Endoplasmic Reticulum Stress. 578 Int J Mol Sci. 4 août 2018;19(8).

579 28. Xu J-L, Li L-Y, Wang Y-Q, Li Y-Q, Shan M, Sun S-Z, et al. Hepatocyte-specific 580 deletion of BAP31 promotes SREBP1C activation, promotes hepatic lipid 581 accumulation, and worsens IR in mice. J Lipid Res. 2018;59(1):350 47. 
584 Table 1: Clinical and molecular features of patients with intragenic pathogenic 585 LoF BCAP31 variants. Reference transcript: NM_001139441.1.

586 abN, abnormal; BG, basal ganglia; C, chronic; CM, cisterna magna; CC, corpus callosum;

587 G, Gastrostomy tube; ID, intellectual disability; I, intermittent; LD, learning disabilities; mat, 588 maternal; nd, not determined; nr, non relevant; $\mathrm{P}$, patient; SNHL, sensorineural hearing loss;

589 subA, subarachnoidal; WM, white matter; VH, vermis hypoplasia

590

591 Table 2: Clinical and molecular features of patients with missense BCAP31 592 variants. Reference transcript: NM_001139441.1.

593 CC, corpus callosum; ID, intellectual disability; mat, maternal; nd, not determined; P, 594 patient; SNHL, sensorineural hearing loss.

595

596 Table 3: Clinical and genetic features of patients with large deletions including 597 BCAP31. Reference transcript: NM_001139441.1.

598 CC, corpus callosum; DD, developmental delay; G, Gastrostomy tube; mat, maternal; 599 nd, not determined; nr, non relevant; P, patient; SNHL, sensorineural hearing loss; 600 VD, ventricular dilatation; WM, white matter.

601

602 Figure 1: scheme of BCAP31 gene showing the LoF and missense variants 603 identified in published patients and those of our study. The variants identified in 604 patients of our study are located above the gene, and those previously reported are 605 underneath the gene. Reference transcript: NM_001139441.1. Exons are numbered 606 according to Cacciagli et al. 2013. and correspond to transcript 607 ENST00000458587.8. Full splice variant denomination is 608 NC_000023.11(NM_001139441.1):g.153723152C>T for P2 and P3; and 609 NC_000023.11(NM_001139441.1):g.153702006C>T for P8.

611 Figure 2: Scheme of BCAP31 and flanking genes, showing large deletions of $612 B C A P 31$ identified in patients of this study and in the literature. On the top, non613 CADDS patients, with deletions including BCAP31 and adjacent genes in 5' 614 (excluding $A B C D 1$ ). On the bottom, CADDS patients with deletions including 615 BCAP31 and ABCD1. Reference transcript: NM_001139441.1. Exons are numbered 
616 according to Cacciagli et al. 2013. and correspond to transcript 617 ENST00000458587.8.

618

619 Figure 3: Facial features of BCAP31 patients. The males P6 and P9 have a LoF 620 variant of $B C A P 31$. $\mathrm{P} 14$ has a missense variant. $\mathrm{P} 13$ is a female with a LoF variant. 621 There does not seem to be a specific facial gestalt for BCAP31 anomalies. Some 622 common features have been noted with deep set eyes, as P6 and P13, hypotonic 623 face as seen in P6, P9 and P14, high nasal bridge for P6, high and narrow bridge for $624 \mathrm{P} 9$ and P13.

625

626 Figure 4: Cerebral MRI of patients 1, 11 and 19. A) Patient 1 (LoF intragenic 627 pathogenic variant). At 2 years old (A1: axial FLAIR, A2, A3, A4: axial T2): signal 628 hyperintensity in the peritrigonal white matter (see arrows in A1), small thalami (see 629 arrows in A3), small cerebral peduncles (see arrows in A2), paired T2 630 hyperintensities in the dorsal pons (see arrows in A4). B) Patient 11 (LoF intragenic 631 pathogenic variant). At 8 months old (B1: sagittal T1, B2: axial FLAIR): markedly 632 decreased white matter as evidenced by a thin corpus callosum (B1 and B2) as well 633 as the sylvian fissures nearly abutting the lateral ventricles (see arrows in B2). C) 634 Patient 19 (deletion of BCAP31 and adjacent genes). At 6 months (C1: sagittal T1, 635 C2: axial T2): decreased white matter, myelination delay, cortical atrophy, thin corpus 636 callosum and ventricular dilatation. At 2 years old (C3: sagittal T2, C4: axial T2): 637 increased white matter anomalies, marked cortical atrophy, vermian atrophy and 638 ventricular dilatation. 
c. $702+1 \mathrm{G}>\mathrm{A}$

p.(?)

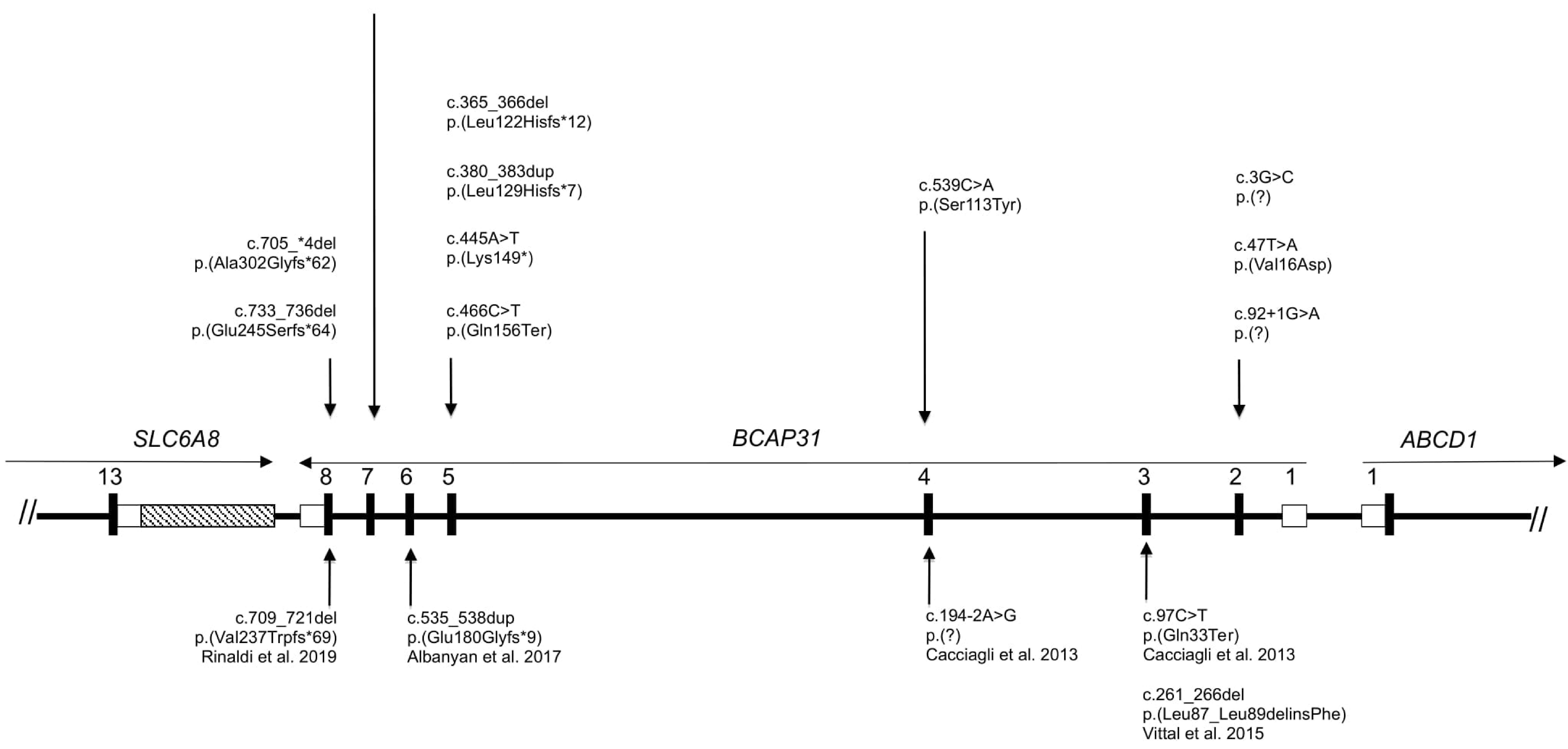

Published 


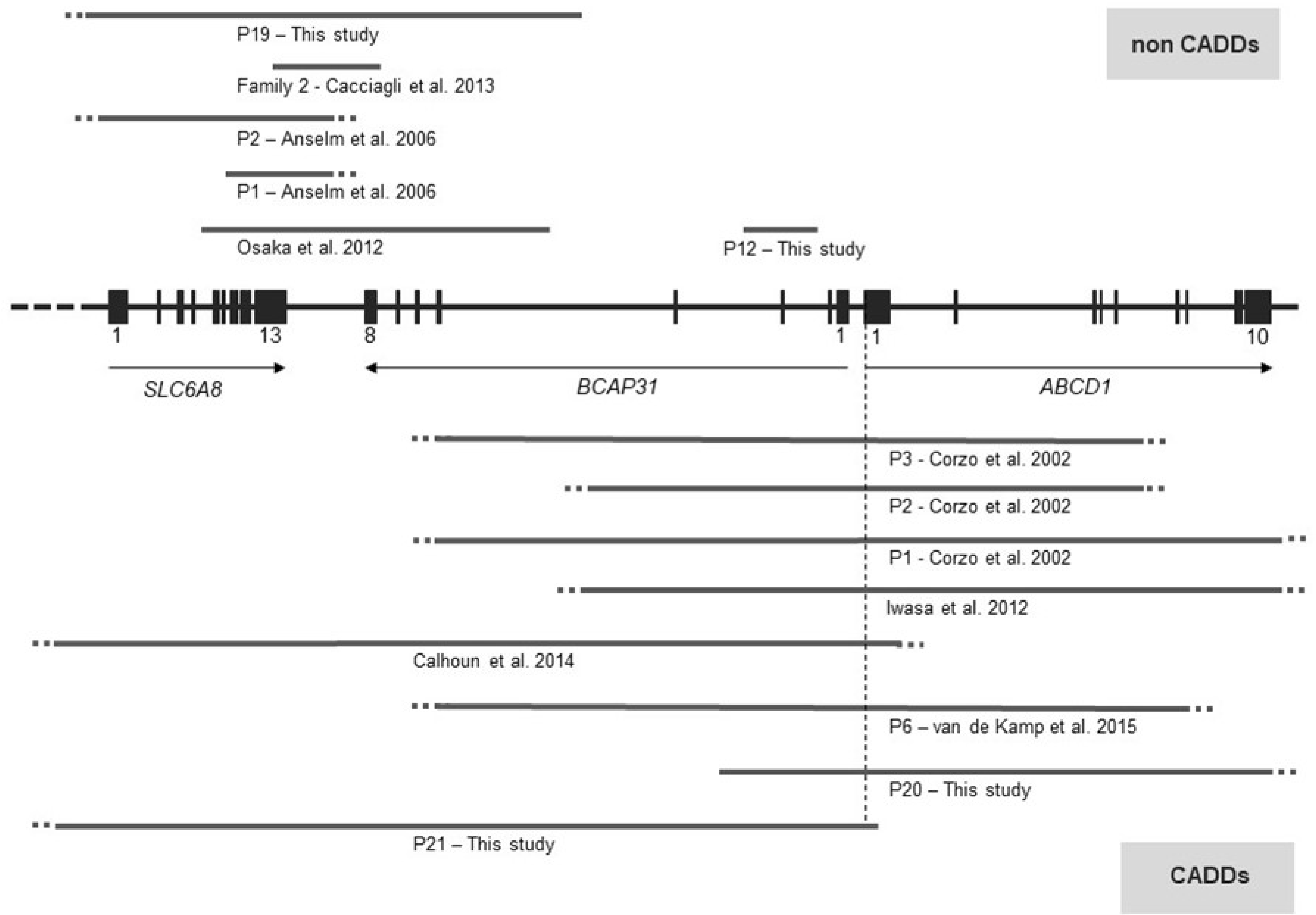




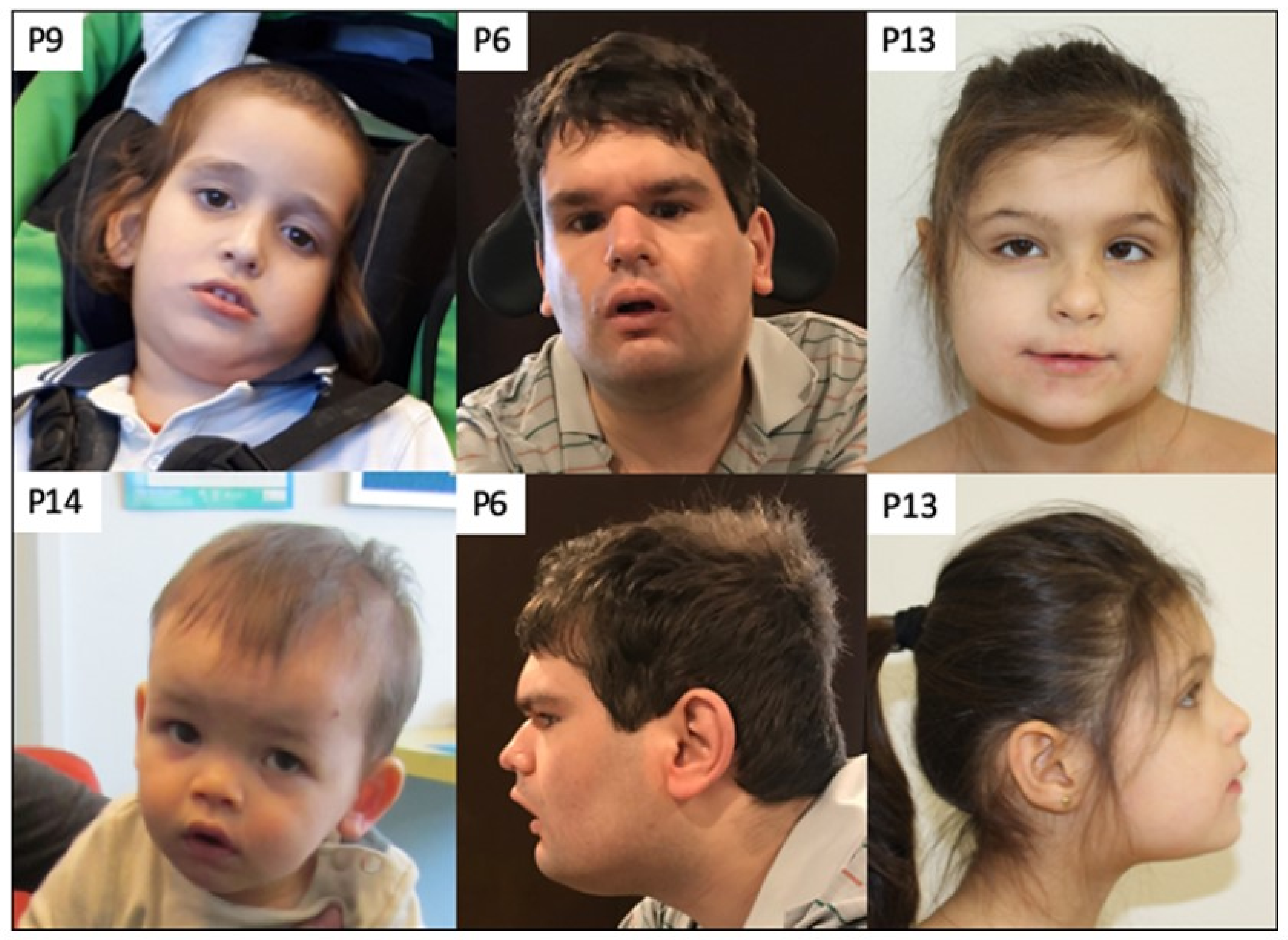




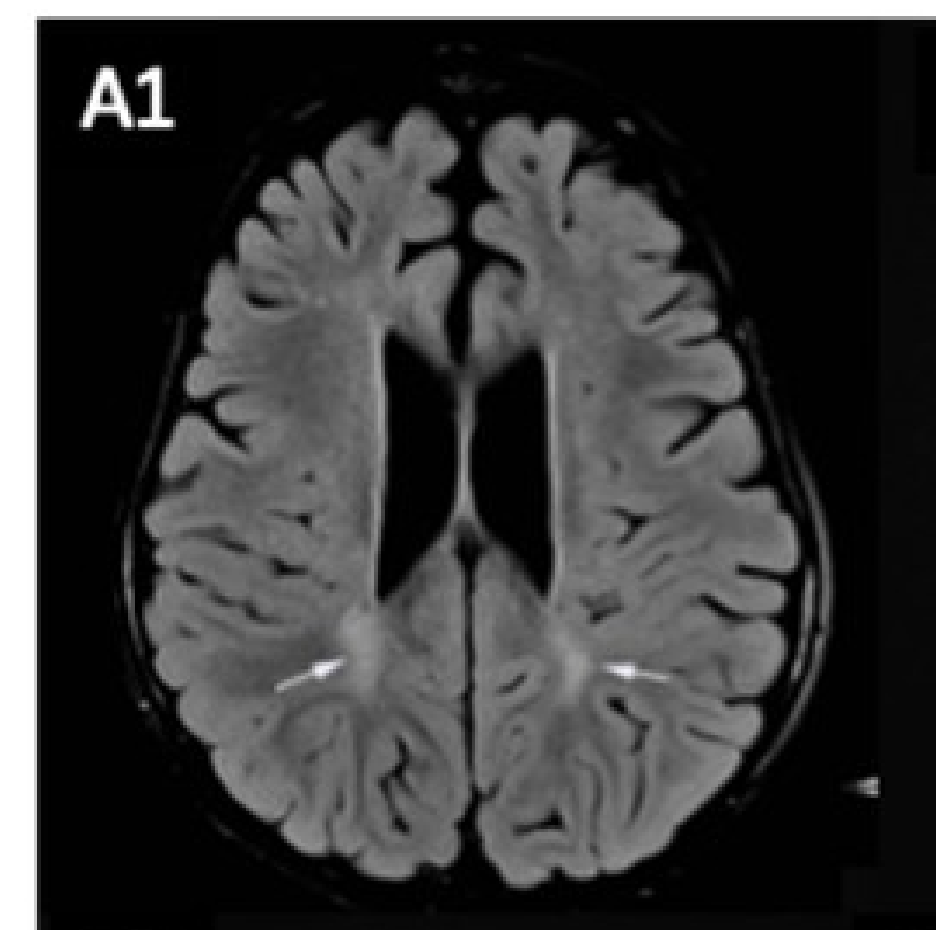

A3

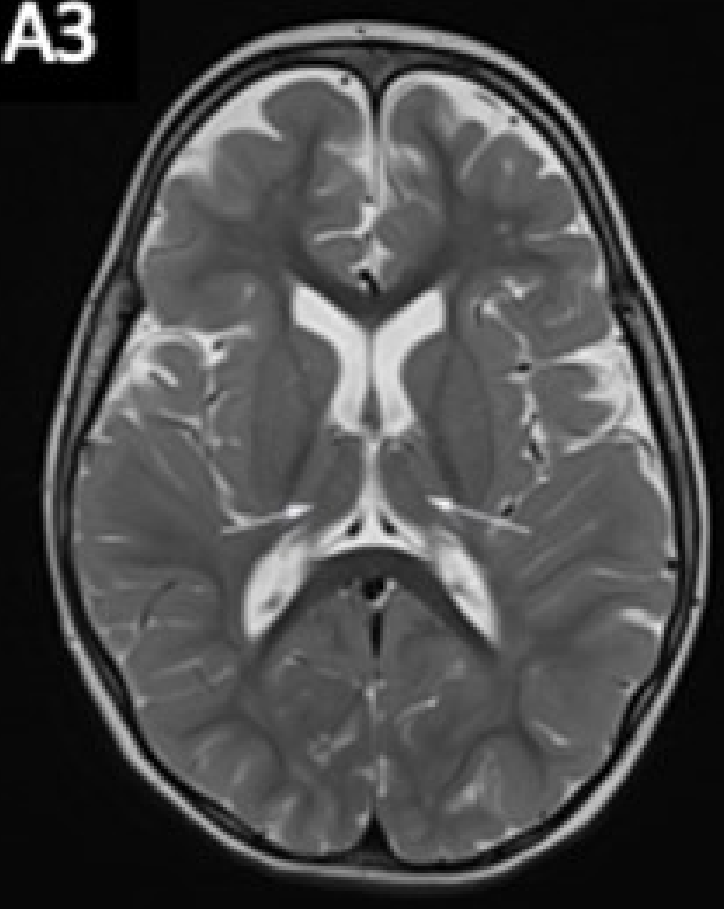

A2

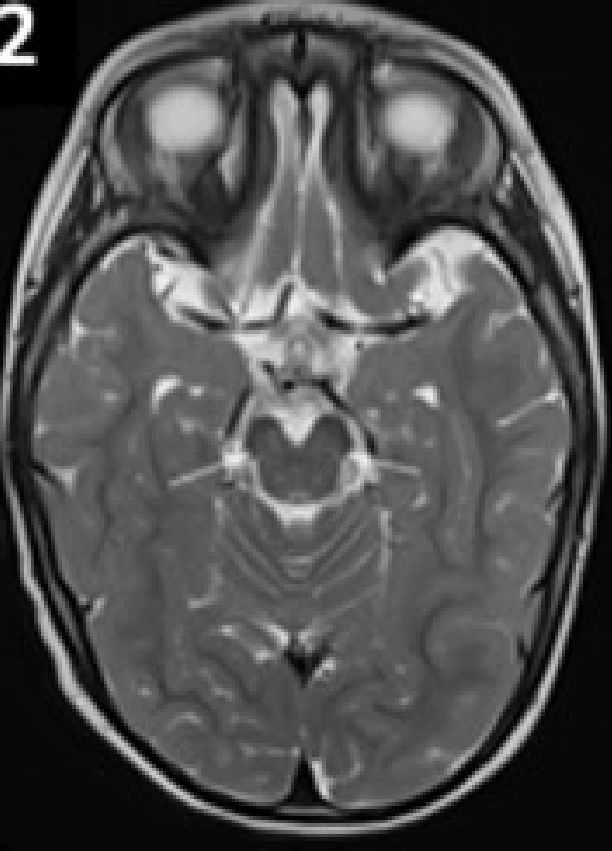

A4

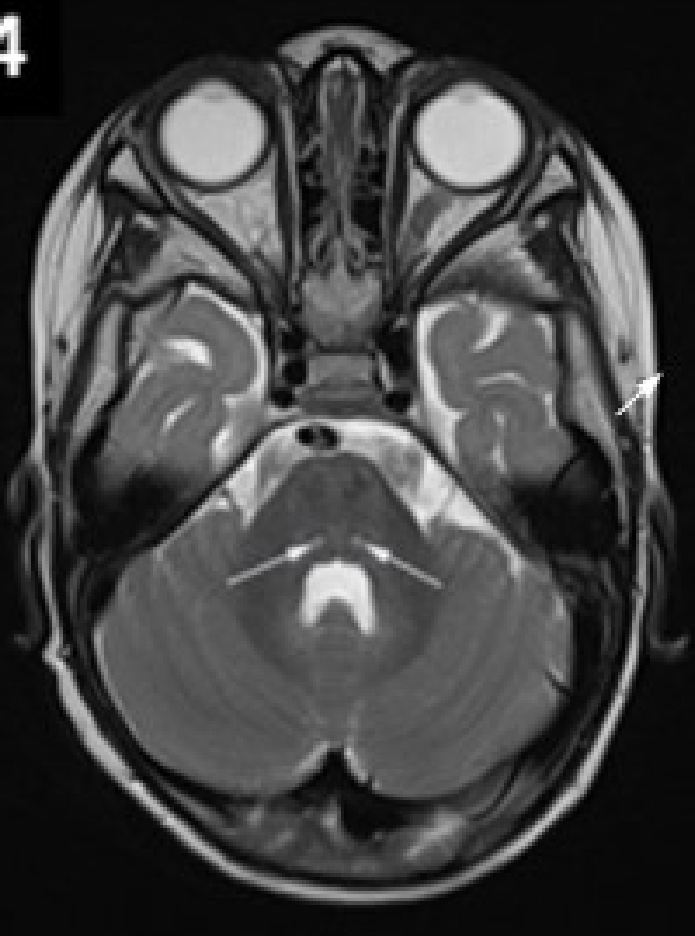

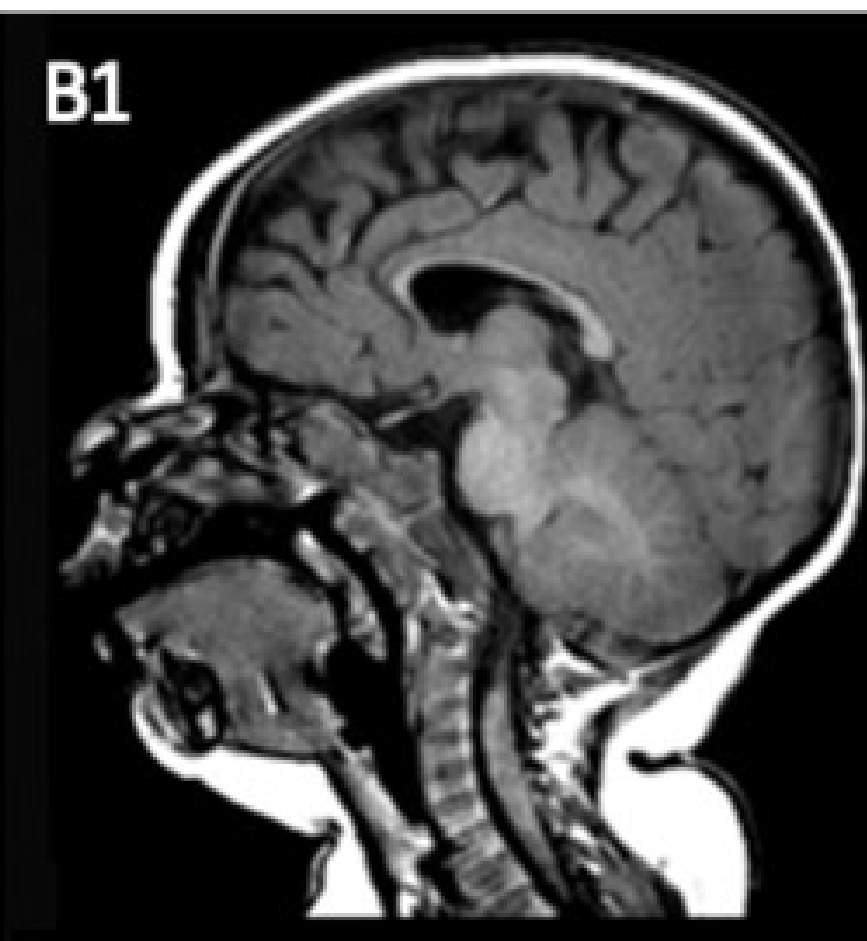

B2

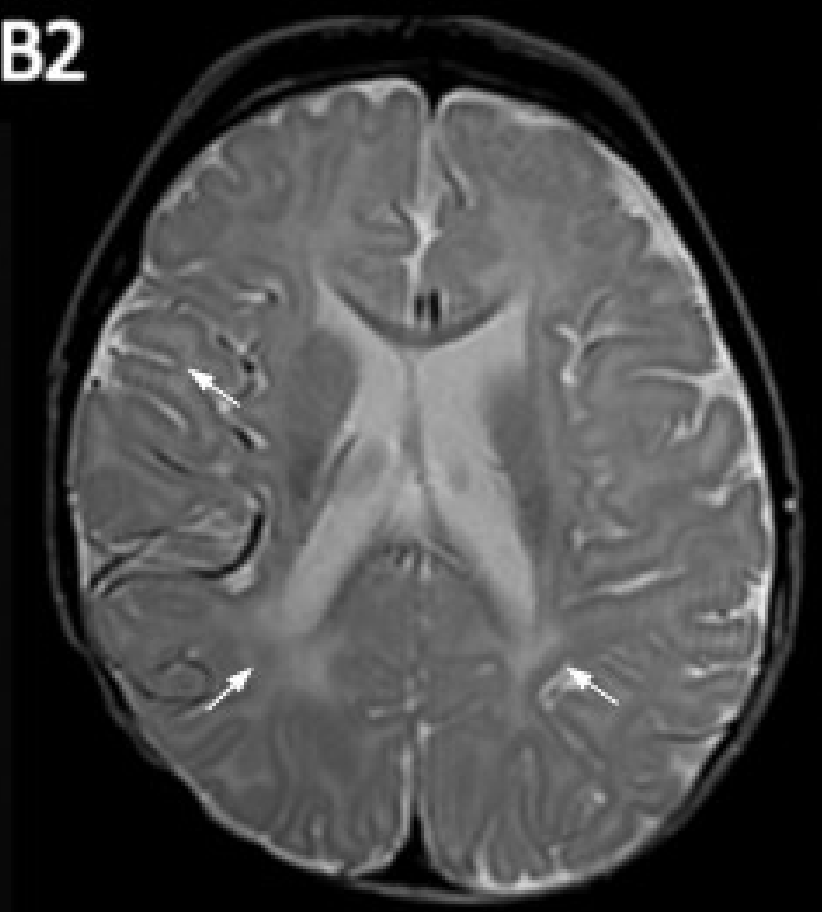

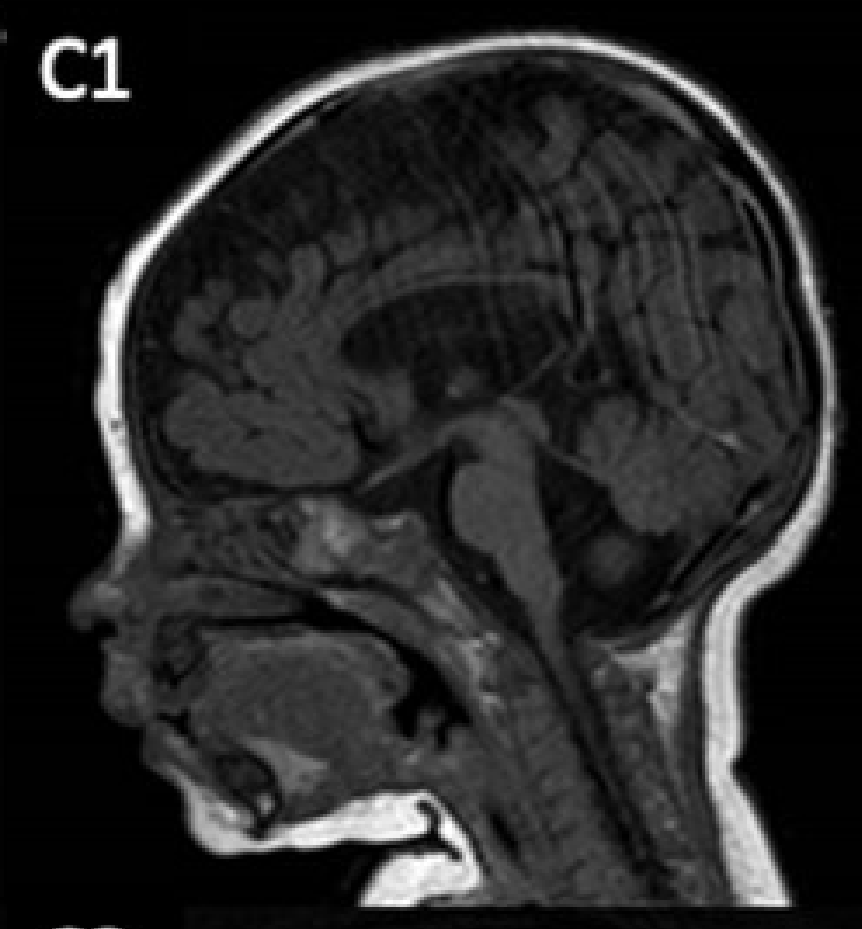

C3

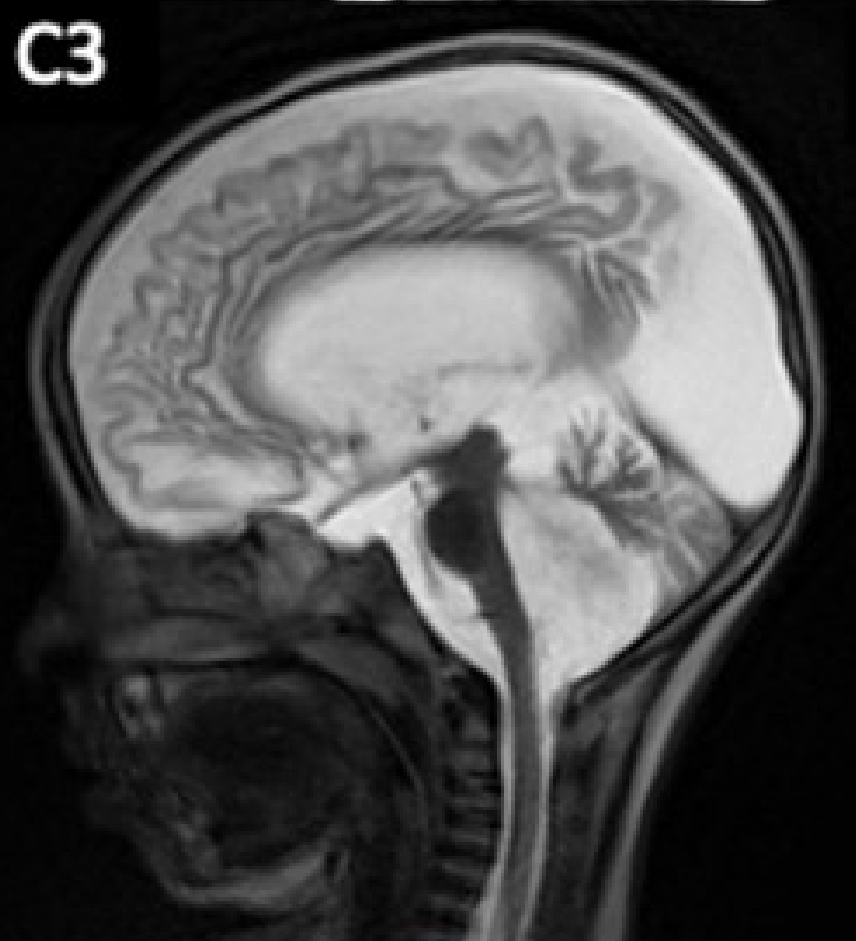

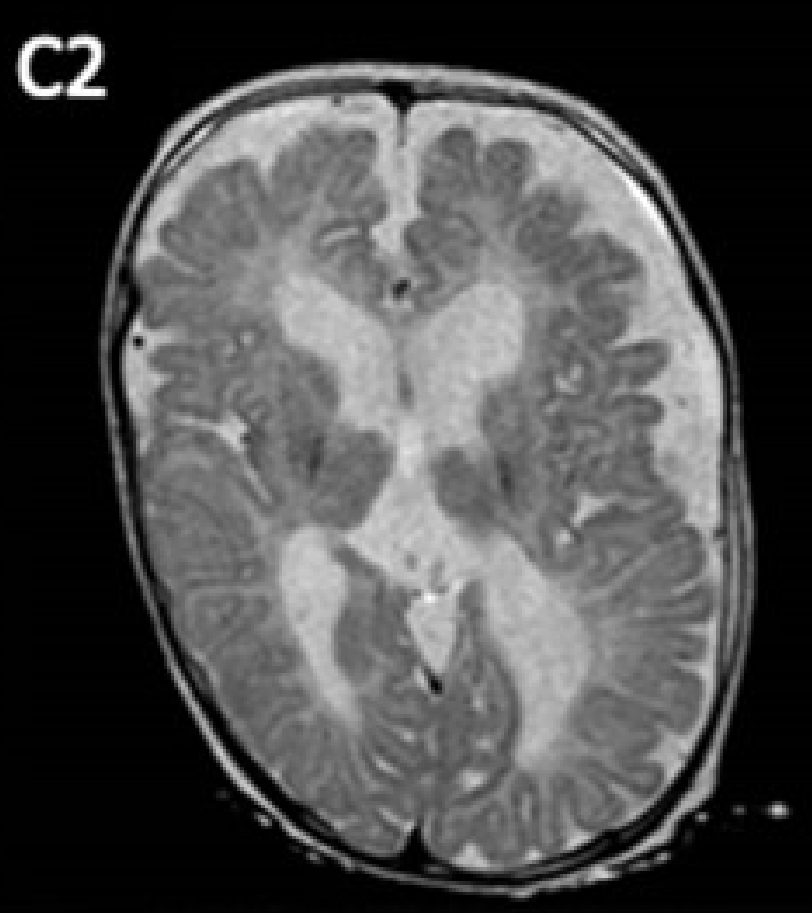

C4

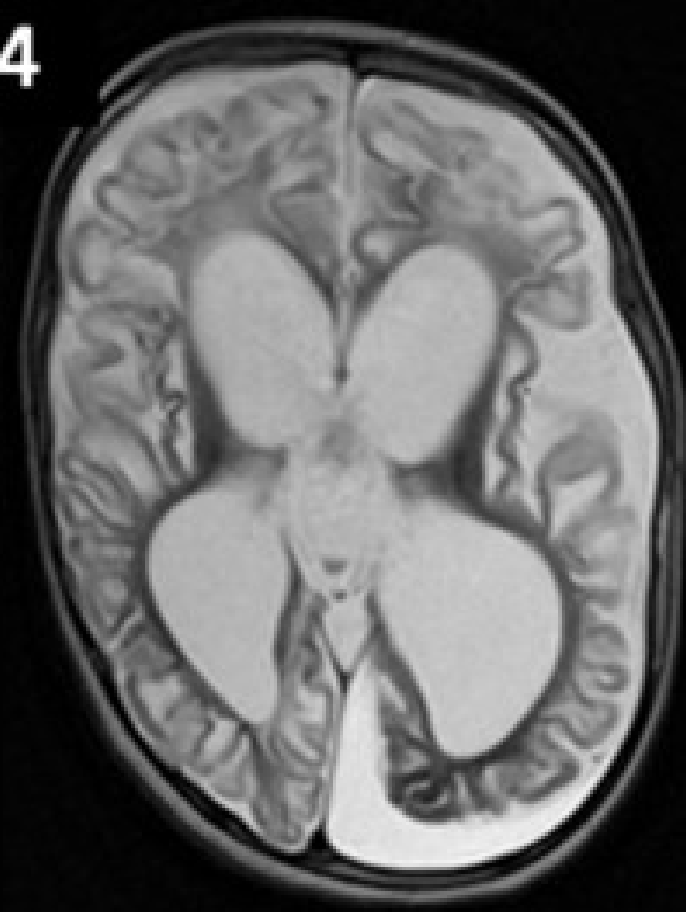


Table 1: Clinical and molecular features of patients with intragenic pathogenic LoF BCAP31 variants. Reference transcript: NM_001139441.1.

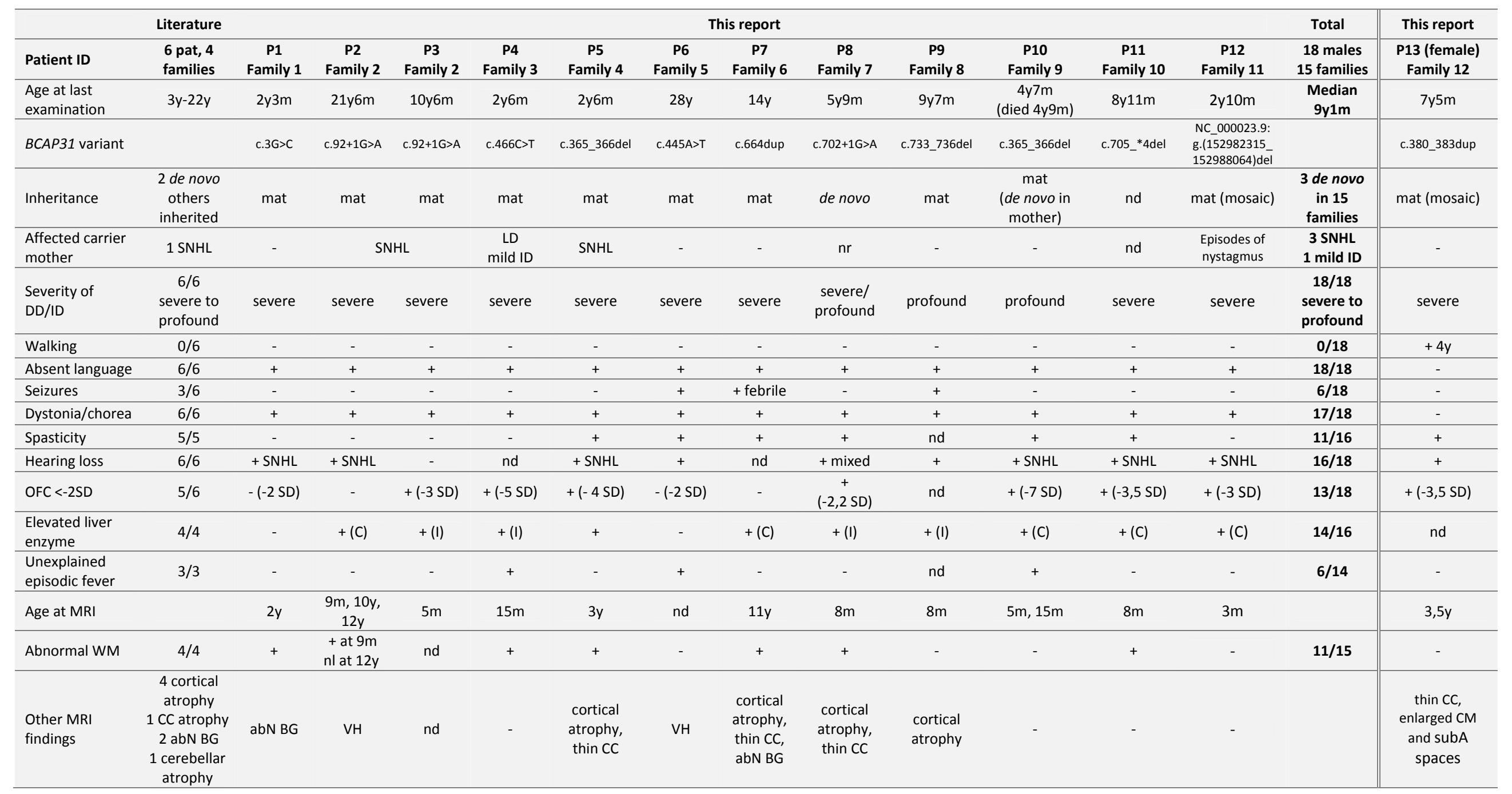

abN, abnormal ; BG, basal ganglia; C, chronic; CM, cisterna magna; CC, corpus callosum; G, Gastrostomy tube; ID, intellectual disability; I, intermittent; LD, learning disabilities; mat, maternal; nd, not determined; nr, non relevant; P, patient; SNHL, sensorineural hearing loss; subA, subarachnoidal; WM, white matter; VH, vermis hypoplasia 
Table 2: Clinical and molecular features of patients with missense BCAP31 variants. Reference transcript: NM_001139441.1.

\begin{tabular}{|c|c|c|c|c|c|c|c|}
\hline Patient ID & $\begin{array}{c}\text { Literature } \\
2 \text { patients } \\
1 \text { family (Vittal et al) }\end{array}$ & $\begin{array}{c}\text { P14 } \\
\text { Family } 13\end{array}$ & $\begin{array}{c}\text { P15 } \\
\text { Family } 14\end{array}$ & $\begin{array}{c}\text { P16 } \\
\text { (uncle of P15) } \\
\text { Family } 14\end{array}$ & $\begin{array}{c}\text { P17 } \\
\text { (uncle of P15) } \\
\text { Family } 14\end{array}$ & $\begin{array}{c}\text { Total } \\
6 \text { patients } \\
3 \text { families }\end{array}$ & $\begin{array}{c}\text { P18 (female) } \\
\text { Family } 14 \\
\text { (cousin of P15, niece of } \\
\text { P16 and P17) }\end{array}$ \\
\hline Sex & M & M & M & $M$ & $M$ & M & $\mathrm{F}$ \\
\hline $\begin{array}{l}\text { Age last } \\
\text { examination }\end{array}$ & $21 y$ (twins) & $3 y$ & $32 y$ & $36 y$ & $29 y$ & $19 y 10 m$ & $19 y$ \\
\hline Variant & $\begin{array}{c}\text { c.261_266del } \\
\text { p.(Leu87_Leu89delinsPhe) }\end{array}$ & $\begin{array}{c}\text { c.47T>A } \\
\text { p.(Val16Asp) }\end{array}$ & $\begin{array}{c}\text { c.338C }>A \\
\text { p.(Ser113Tyr) }\end{array}$ & $\begin{array}{c}\text { c.338C }>A \\
\text { p.(Ser113Tyr) }\end{array}$ & $\begin{array}{c}\text { c.338C }>A \\
\text { p.(Ser113Tyr) }\end{array}$ & & $\begin{array}{c}\text { c.338C>A } \\
\text { p.(Ser113Tyr) }\end{array}$ \\
\hline Inheritance & mat & mat & mat & mat & mat & mat & mat \\
\hline $\begin{array}{l}\text { Affected carrier } \\
\text { mother }\end{array}$ & - & SNHL & late onset seizures & nd & nd & $\begin{array}{l}1 \mathrm{SNLH}, 1 \text { late } \\
\text { onset seizures }\end{array}$ & late onset seizures \\
\hline Severity of ID & Moderate to severe & mild & severe & severe & moderate & $\begin{array}{l}\text { Moderate to } \\
\text { severe }\end{array}$ & mild \\
\hline Sitting & $0 / 2$ & + & + & nd & + & $2 / 4$ & + \\
\hline Walking & $0 / 2$ & - & - & - & + ataxic & $1 / 6$ & $+17 m$ \\
\hline Language & $1 / 2$ (partial) & + words & $\begin{array}{c}+ \text { words } \\
\text { communicates with } \\
\text { ipad }\end{array}$ & $\begin{array}{l}\text { + words } \\
\text { dysarthria }\end{array}$ & + sentences dysarthria & $5 / 6$ & $\begin{array}{l}\text { + delayed } \\
\text { dysarthria }\end{array}$ \\
\hline Seizures & nd & - & - & - & - & $0 / 4$ & + drop attacks \\
\hline Dystonia/chorea & $2 / 2$ & + & + & + & + & $6 / 6$ & - \\
\hline Spasticity & nd & nd & - & + & - & $1 / 3$ & - \\
\hline Hearing loss & $2 / 2$ & $+\mathrm{SNHL}$ & + conductive & - & - & $4 / 6$ & - \\
\hline OFC $<-2 S D$ & nd & - & - & + & nd & $1 / 3$ & - \\
\hline $\begin{array}{l}\text { Elevated Liver } \\
\text { enzyme }\end{array}$ & nd & - & - & nd & nd & $0 / 1$ & nd \\
\hline $\begin{array}{l}\text { Unexplained } \\
\text { episodic fever }\end{array}$ & nd & - & - & - & - & $0 / 4$ & - \\
\hline Age at MRI & nd & $14 m$ & & & & & $18 y$ \\
\hline Abnormal MRI & $1 / 1$ & - & nd & nd & nd & $1 / 2$ & - \\
\hline Other & $\begin{array}{l}\text { Cerebral MRI showed } \\
\text { delayed myelination, } \\
\text { atrophy of posterior } \\
\text { ocipital lobes, thin CC, } \\
\text { hypoplasia of superior } \\
\text { cerebrellar vermis }\end{array}$ & $\begin{array}{l}\text { SNHL in } 3 \text { other } \\
\text { female carriers. An } \\
\text { uncle of P15 } \\
\text { presumably had the } \\
\text { same condition } \\
\text { although DNA was } \\
\text { not available for } \\
\text { testing }\end{array}$ & $\begin{array}{l}\text { Recurrent pneumonia. } \\
\text { Swallowing difficulties. }\end{array}$ & $\begin{array}{c}\text { Collapse due to severe } \\
\text { dehydration and } \\
\text { hypernatremia at } 6 \mathrm{~m} \\
\text { Died at } 36 \mathrm{y} \text { of twisted } \\
\text { bowel }\end{array}$ & & & ataxic gait \\
\hline
\end{tabular}

CC, corpus callosum; ID, intellectual disability; mat, maternal; nd, not determined; P, patient; SNHL, sensorineural hearing loss. 
Table 3: clinical and genetic features of patients with large deletions including BCAP31. Reference transcript: NM_001139441.1

\begin{tabular}{|c|c|c|c|c|c|}
\hline \multirow[b]{2}{*}{ Patient ID } & \multirow{2}{*}{$\begin{array}{c}\text { Literature } \\
7 \text { patients } \\
\text { (7 families) }\end{array}$} & \multicolumn{2}{|c|}{ This report } & \multirow{2}{*}{$\begin{array}{c}\text { Total } \\
9 \text { male } \\
\text { patients }\end{array}$} & \multirow{2}{*}{$\begin{array}{c}\text { This report } \\
\text { P21 (female) } \\
\text { Family } 17\end{array}$} \\
\hline & & $\begin{array}{c}\text { P19 } \\
\text { Family } 15\end{array}$ & $\begin{array}{c}\text { P20 } \\
\text { Family } 16\end{array}$ & & \\
\hline Age & $4 m-11 m$ & $3 y$ & $16 \mathrm{~m}$ (deceased) & $4 m-16 m$ & $3 y$ \\
\hline Variant & See figure 2 & $\begin{array}{l}\text { NC_000023.10: } \\
\text { g.(152886255- } \\
\text { 152976269)del }\end{array}$ & $\begin{array}{l}\text { NC_000023.10: } \\
\text { g.(152982350_- } \\
\text { 153041544)del }\end{array}$ & & $\begin{array}{l}\text { NC_000023.10: } \\
\text { g.(152882907_- } \\
\text { 152991027)del }\end{array}$ \\
\hline Inheritance & $\begin{array}{c}2 / 5 \\
\text { de novo }\end{array}$ & de novo & de novo & $\begin{array}{c}4 / 7 \\
\text { de novo }\end{array}$ & nd \\
\hline $\begin{array}{l}\text { Affected carrier } \\
\text { mother }\end{array}$ & nd & $\mathrm{nr}$ & $\mathrm{nr}$ & nd & nd \\
\hline Severity of DD & $\begin{array}{c}7 / 7 \\
\text { severe to } \\
\text { profound }\end{array}$ & profound & profound & $\begin{array}{c}9 / 9 \\
\text { severe to } \\
\text { profound }\end{array}$ & moderate \\
\hline Walking & $\mathrm{nr}$ & - & $\mathrm{nr}$ & & $+2 y$ \\
\hline $\begin{array}{l}\text { Absent or limited } \\
\text { language }\end{array}$ & $\mathrm{nr}$ & + & $\mathrm{nr}$ & & + rare words \\
\hline Seizures & $3 / 6$ & + spasms & - & $4 / 8$ & - \\
\hline Dystonia/chorea & $1 / 6$ & - & + & $2 / 8$ & - \\
\hline Spasticity & nd & + & - & $1 / 2$ & - \\
\hline Hearing loss & $5 / 7$ & + & - & $6 / 9$ & + \\
\hline OFC $<-2 S D$ & $2 / 2$ & - & + & $3 / 4$ & - \\
\hline Liver dysfunction & $\begin{array}{c}7 / 7 \\
\text { cholestasis }\end{array}$ & $\begin{array}{l}\text { reversible acute } \\
\text { liver failure }\end{array}$ & $\begin{array}{c}\text { moderate } \\
\text { enzyme } \\
\text { elevation }\end{array}$ & $9 / 9$ & $\begin{array}{c}\text { cholestasis, } \\
\text { intermittent } \\
\text { enzyme } \\
\text { elevation, } \\
\text { hepatic failure }\end{array}$ \\
\hline $\begin{array}{l}\text { Cholangiopathy on } \\
\text { Liver biopsy }\end{array}$ & $3 / 3$ & nd & nd & $3 / 3$ & + \\
\hline Adrenal dysfunction & $3 / 7 ?$ & - & + & $4 / 9$ & nd \\
\hline Age at MRI & & $2 y$ & $2 \mathrm{~m}, 10 \mathrm{~m}$ & & $15 \mathrm{~m}$ \\
\hline Abnormal WM & $4 / 5$ & + & - & $5 / 6$ & + \\
\hline Other cMRI findings & $\begin{array}{c}1 \text { thin } C C, 1 \\
\text { VD }\end{array}$ & $\begin{array}{l}\text { cerebellar } \\
\text { atrophy }\end{array}$ & $\begin{array}{c}\text { pulvinar } \\
\text { hyperintensity }\end{array}$ & & $\begin{array}{l}\text { cerebellar } \\
\text { atrophy, VD }\end{array}$ \\
\hline
\end{tabular}

CC, corpus callosum; DD, developmental delay; G, Gastrostomy tube; mat, maternal; nd, not determined; nr, non relevant; P, patient; SNHL, sensorineural hearing loss; VD, ventricular dilatation; WM, white matter. 